\title{
Traumatic Spinal Cord Injury Care in Canada: A Survey of Canadian Centers
}

\author{
Vanessa K. Noonan, Elaine Chan,, Argelio Santos,, Lesley Soril, Rachel Lewis, ${ }^{2}$ Anoushka Singh,3 \\ Christiana L. Cheng,, Colleen O'Connell, ${ }^{4}$ Catherine Truchon, Jérôme Paquet, ${ }^{6}$ Sean Christie, \\ Karen Ethans, Eve Tsai, Michael H. Ford, ${ }^{10}$ Brian Drew, ${ }^{11}$ A. Gary Linassi, ${ }^{12}$ \\ Christopher S. Bailey, ${ }^{13}$ Michael G. Fehlings ${ }^{14}$ and the RHSCIR Network
}

\begin{abstract}
Specialized centers of care for persons sustaining a traumatic spinal cord injury (tSCI) have been established in many countries, but the ideal system of care has not been defined. The objective of this study was to describe care delivery, with a focus on structures and services, for persons with tSCI in Canada. A survey was sent to 26 facilities (12 acute, 11 rehabilitation, and three integrated) from eight provinces participating in the Access to Care and Timing project. The survey included questions about: 1) care provision; 2) structural attributes and; 3) service availability. Survey completion rate was $100 \%$. Data sources used to complete the survey were the Rick Hansen Spinal Cord Injury Registry, other hospital databases, clinical protocols, and subject matter experts. Acute and rehabilitation care provided by integrated facilities were described separately, resulting in data from 15 acute and 14 rehabilitation facilities. The number of admissions for tSCI over a 12-month period between 2009-2011 ranged from 17 to 104 (median 39), and 11 to 96 (median 32 ), for acute and rehabilitation facilities, respectively. Grouping of patients was reported by 8/15 acute and 10/14 rehabilitation facilities. Criteria for admission to the inpatient rehabilitation facilities varied among facilities ( 25 different criteria reported). Results from the survey revealed similarities in the basic structure and the provision of general services, but also some differences in the degree of specialization of care for persons with tSCI. Continued work on the impact of specialized care for both the patient and healthcare system is needed.
\end{abstract}

Keywords: care provision; services; structures; specialized care; spinal cord injury

\section{Introduction}

$\mathbf{P}$ ATIEnTs Sustaining CRitical CONDitions such as major trauma benefit from specialized care as opposed to general care. ${ }^{1}$ The creation of trauma centers and trauma programs following the publication of Accidental Death and Disability:
The Neglected Disease of Modern Society in 1966 dramatically altered how patients with major life-threatening injuries are treated. ${ }^{2}$ Since the release of this report, research has demonstrated the need for further specialization to address the unique needs of patient populations, such as those with spinal cord injury (SCI). ${ }^{3}$

\footnotetext{
${ }^{1}$ Rick Hansen Institute, Vancouver, British Columbia, Canada.

${ }^{2}$ Centre for Operations Excellence, Sauder School of Business, University of British Columbia, Vancouver, British Columbia, Canada.

${ }^{3}$ Spinal Cord Injury Clinical Research Unit, Toronto Western Hospital, Toronto, Ontario, Canada.

${ }^{4}$ Division of Physical Medicine and Rehabilitation, ${ }^{7}$ Division of Neurosurgery, Dalhousie University, Halifax, Nova Scotia, Canada.

${ }^{5}$ Trauma and Critical Care Evaluation Unit, Institut national d'excellence en santé et en services sociaux, Québec City, Québec, Canada.

${ }^{6}$ Department of Surgery, Université Laval, Québec City, Québec, Canada.

${ }^{8}$ Department of Medicine, University of Manitoba, Winnipeg, Manitoba, Canada.

${ }^{9}$ Department of Surgery, University of Ottawa, Ottawa, Ontario, Canada.

${ }^{10}$ Orthopedic Spine and Trauma, Integrated Spine Unit, Sunnybrook Health Sciences Center, Toronto, Ontario, Canada.

${ }^{11}$ Department of Orthopedic Surgery, McMaster University, Hamilton, Ontario, Canada.

${ }^{12}$ Department of Physical Medicine and Rehabilitation, University of Saskatchewan, Saskatoon, Saskatchewan, Canada.

${ }^{13}$ Department of Surgery, Western University, London, Ontario, Canada.

${ }^{14}$ Department of Surgery, University of Toronto, Toronto, Ontario, Canada.
}

(c) Vanessa K. Noonan et al., 2017; Published by Mary Ann Liebert, Inc. This Open Access article is distributed under the terms of the Creative Commons Attribution Noncommercial License (http://creativecommons.org/licenses/by-nc/4.0/) which permits any noncommercial use, distribution, and reproduction in any medium, provided the original author(s) and the source are credited. 
The first SCI center was pioneered by Donald Munro in 1936 at the Boston City Hospital, Massachusetts. ${ }^{4}$ Drawing from the work of Munro, Sir Ludwig Guttmann established an SCI unit at the Stoke Mandeville Hospital in 1944 that became a model for future studies. ${ }^{5}$ Utilizing a team approach to care, Guttmann demonstrated the benefits of early prevention of secondary complications after SCI and the importance of rehabilitation in addition to acute care. ${ }^{5}$ Current evidence shows that timely admission to a comprehensive center for SCI is linked to decreased length of stay (LOS) ${ }^{6-8}$ and decreased incidence of secondary complications. ${ }^{7,8}$

Although dedicated SCI centers have since been established in many countries, a systematic review by Parent and colleagues ${ }^{3}$ examining the impact of specialized centers concluded that the ideal system of healthcare delivery for persons with traumatic SCI (tSCI) has not been defined. However, several recommended attributes of specialized care in the acute phase were identified, which included admitting a certain volume of individuals with tSCI (exact number not yet defined), location near a Level I trauma center, 24-h access to magnetic resonance imaging (MRI) and an operating room, provision of a "spinal unit," and referral to a rehabilitation program that specializes in SCI. ${ }^{3}$

Level I trauma centers (based on resources, patient volume, education, and research activities) have demonstrated superior patient outcomes, such as reduced patient mortality ${ }^{9,10}$ and improved function, ${ }^{10,11}$ compared with Level II and community centers. Organized trauma systems with established transfer agreements also have been shown to reduce mortality. ${ }^{12,13}$ Further, a number of studies have demonstrated that specialized acute care for tSCI results in better outcomes, including lower mortality rates, ${ }^{14}$ fewer complications, ${ }^{14-16}$ greater potential for neurological recovery, ${ }^{14,17}$ decreased LOS, ${ }^{14,15,17}$ and an overall reduction in costs. ${ }^{14}$ Early admission to rehabilitation following injury also has been shown to be beneficial, resulting in, for example, shorter LOS, ${ }^{18}$ improved functional status, ${ }^{18,19}$ greater rates of functional gain, ${ }^{20}$ and fewer complications. ${ }^{21,22}$

Few studies have compared care delivery after SCI internationally. ${ }^{23-27}$ A challenge to comparing care in Canada with care internationally is the paucity of information available. An environmental scan of Canadian SCI rehabilitation centers, however, has described service delivery and current resources available for specific rehabilitation goals and issues (e.g., skin integrity, mobility, bowel, bladder, and sexual health) ${ }^{28}$ Additionally, Accreditation Canada has developed comprehensive, evidence-based standards for acute and rehabilitation SCI services to help standardize and optimize care for persons with SCI in Canada. ${ }^{29,30}$ The objective of this study, therefore, is to describe provincial- and facility-level acute and rehabilitation care delivery, with a particular focus on the structures and services based on the recommended criteria outlined by Parent and colleagues, ${ }^{3}$ for patients with tSCI at 26 major facilities in the Canadian SCI Network, which provide care for the majority of individuals who sustain an acute tSCI.

\section{Methods}

\section{Survey}

A survey was developed as part of the Access to Care and Timing (ACT) project sponsored by the Rick Hansen Institute (RHI) to examine current models of care delivery for tSCI in Canada and how the provision of care impacts outcomes along the continuum of care. ${ }^{31}$ Survey questions were related to: 1 ) care within the province and within each facility (e.g., regions served, number of beds); 2) structural attributes (e.g., number of wards available for admissions); and 3) service availability (e.g., admission criteria). Facilities were instructed to answer the questions based on care delivery from 2009 to 2011 . A copy of the survey is included in the Supplementary Material (see online supplementary material at www.liebertpub.com).

The survey was administered to a purposive sample of $26 \mathrm{tSCI}$ care facilities located in 13 cities within eight Canadian provinces: 12 acute, 11 rehabilitation, and three integrated acute and rehabilitation facilities (herein referred to as integrated facilities). Each participating facility is also part of the Rick Hansen Spinal Cord Injury Registry (RHSCIR), which is a national longitudinal registry documenting the continuum of care in Canada for tSCI. ${ }^{32}$ The RHSCIR has expanded since it was established in 2004 and this study included all facilities enrolled as of January 2011. Facilities were excluded if: a) they were not enrolled in the RHSCIR, and b) they were located in provinces or territories where patients with tSCI are triaged and treated in neighboring provinces. Despite these sampling exclusions, it was assumed that the majority of individuals with an acute tSCI in Canada would be treated at one of the participating facilities. These facilities are situated in metropolitan areas in the southernmost portion of Canada where $69 \%$ of the Canadian population resides. ${ }^{33}$ All facilities obtained research ethics board approval, if required, and institutional approval to disclose the survey results to the RHI. Permission was also given by all participating facilities to disclose their identity.

\section{Data sources}

Completion of the survey by the participating facilities required data from several sources. Administrative and clinical personnel were contacted to assist with responses regarding the structure and availability of services at each facility. Where possible, data were obtained from the RHSCIR at each facility to determine quantifiable estimates of the number of admissions. If RHSCIR data were not available, the facilities were advised to use other hospital databases. Due to variation in data sources, admission data was reported over any complete 12-month period (calendar or fiscal year) from 2009 to 2011. Subject matter experts assisted in the data cleaning.

\section{Analyses}

The survey results (categorical and continuous data) were analyzed using descriptive statistics. For both the acute and rehabilitation facilities, data were analyzed to describe care within both the province and the facility, the structure of the facility, and the services provided. In addition, experts at each facility were asked a number of open-ended questions to examine potential challenges to providing care for patients with tSCI. Such questions included: "What are the greatest challenges with regards to SCI patient care encountered by your center?" Barriers to the provision of care were identified inductively through thematic analysis of responses.

\section{Results}

Twenty-nine completed surveys were obtained from all 26 participating facilities (12 acute, 11 rehabilitation, and three integrated) resulting in a $100 \%$ response rate. Responses from the integrated facilities are presented by phase of care (vs. by facility), resulting in data from 15 acute and 14 rehabilitation facilities. At the time the surveys were issued, facilities in Newfoundland and the acute facility in New Brunswick had not joined the RHSCIR and therefore their data were not included. Facilities in Prince Edward Island (PEI) and the Territories (Yukon, North West Territories, and Nunavut) were not included as the majority of patients with tSCI from these regions were reported to be triaged and treated in neighboring provinces (e.g., those from PEI may be triaged and treated in Nova Scotia). ${ }^{34}$ 
Overview of provincial acute and rehabilitation healthcare systems

An overview of the acute and rehabilitation facilities is outlined in Tables 1 and 2, respectively. Facilities surveyed from British Columbia, Alberta, Manitoba, Ontario, Nova Scotia, and New Brunswick reported serving one or more neighboring provinces.

The majority of acute care facilities reported to operate primarily as Level I trauma centers (Table 1). There was quite a range in the reported capacity, with the majority having total bed counts greater than 250 . The number of beds available for SCI admissions ranged from 12 to 94 for 13/15 facilities, with two reporting no specific allocation.

Following acute care, persons with tSCI may be eligible for admission to an inpatient rehabilitation program at one of the 14 RHSCIR rehabilitation facilities (Table 2). In contrast to acute care, the rehabilitation facilities reported a narrower range in capacity, with 10/14 facilities having less than 100 beds. The number of beds available for SCI admissions ranged from 10 to 60 . Only one facility (Toronto Rehabilitation Institute) reported to exclusively treat patients with SCI.

\section{Structure and services of SCI care in acute and rehabilitation facilities in Canada}

An overview of the structure and services of the participating facilities are outlined in Tables 3 and $4 \mathrm{~A}-4 \mathrm{~B}$, respectively. It is important to note that the information presented in Tables 3 and 4A-4B (with the exception of inpatient volume which was reported for tSCI only) reflected the care delivery for both traumatic and non-traumatic SCI (ntSCI), as inpatient care for these different subtypes was not segregated at the participating facilities. The primary structural attributes (Table 3 ) and the care services (Table 4A4B) highlighted were based on recommendations of a specialized SCI center. ${ }^{3}$

Among the acute care facilities, reported annual tSCI admissions ranged from 17 to 104 (median 39; Table 3). Approximately half of the acute facilities identified two units or wards that SCI inpatients can be admitted to for the majority of their acute stay. Half of the facilities also reported grouping patients with SCI (i.e., the ward consisting of patients with traumatic and non-traumatic SCI most exclusively). Twelve of the 15 facilities reported $24 \mathrm{~h} / 7$ days a week availability of diagnostic imaging (MRI) and surgical services (Table 4A).

The annual tSCI inpatient admissions reported by the participating rehabilitation facilities were similar to those in the acute care, ranging from 11 to 96 (median 32; Table 3). Grouping of patients with SCI was reported by $10 / 14$ facilities. Most facilities reported only one unit for tSCI inpatient admissions. Referral to the rehabilitation facilities was reported to occur primarily via a personal physiatry consultation at $11 / 15$ acute care facilities, wherein the physiatrist would assess the admissibility and readiness for rehabilitation (Table 4B). A total of 25 different criteria for

Table 1. Overview of the Acute Care Facilities in Canada Participating in the Survey

\begin{tabular}{|c|c|c|c|c|c|c|}
\hline Province/city & Facility & $\begin{array}{c}\text { Trauma } \\
\text { designation } \\
\text { level }\end{array}$ & Regions served & $\begin{array}{l}\text { Total } \\
\text { number } \\
\text { of beds }\end{array}$ & $\begin{array}{l}\text { Beds } \\
\text { available } \\
\text { for SCI } \\
\text { admissions }\end{array}$ & $\begin{array}{l}\text { Admissions } \\
\text { of } t \text { SCI }\end{array}$ \\
\hline BC, Vancouver & Vancouver General Hospital & I & $\mathrm{BC}$ & 955 & 32 & 104 \\
\hline $\mathrm{AB}$, Edmonton & Royal Alexandra Hospital & II & $\begin{array}{l}\text { Northern AB, Northeastern } \\
\text { BC, Yukon }\end{array}$ & 841 & 28 & 30 \\
\hline $\mathrm{AB}$, Edmonton & $\begin{array}{l}\text { Walter Mackenzie Health } \\
\text { Sciences Centre, University } \\
\text { of Alberta Hospital }\end{array}$ & I & $\begin{array}{l}\text { Northern AB, Northwestern } \\
\text { BC, Northern SK, } \\
\text { Northwest Territories }\end{array}$ & 770 & 30 & 39 \\
\hline AB, Calgary & Foothills Hospital & I & Calgary, Southern AB & 927 & 52 & 27 \\
\hline SK, Saskatoon & Royal University Hospital & I & Northern SK & 550 & 82 & 24 \\
\hline MB, Winnipeg & Winnipeg Health Sciences Centre & $\mathrm{I}$ & $\begin{array}{l}\text { MB, Northwestern ON, } \\
\text { Nunavut }\end{array}$ & 800 & 58 & 40 \\
\hline ON, Toronto & Sunnybrook Health Sciences Centre & I & $\mathrm{ON}$ & 1212 & 72 & 40 \\
\hline ON, Toronto & St. Michael's Hospital & I & $\mathrm{ON}$ & 500 & 94 & 50 \\
\hline ON, Toronto & Toronto Western Hospital & $\mathrm{I}^{*}$ & Greater Toronto Area & 236 & 12 & 51 \\
\hline ON, London & $\begin{array}{l}\text { Victoria Hospital, London Health } \\
\text { Sciences Centre }\end{array}$ & I & Southwestern ON & 400 & 41 & 17 \\
\hline ON, Ottawa & The Ottawa Hospital, Civic Campus & I & Champlain LHIN & 453 & $\dagger$ & 25 \\
\hline ON, Hamilton & Hamilton Health Sciences Centre & I & $\begin{array}{l}\text { Hamilton Niagara } \\
\text { Haldimand Brant LHIN }\end{array}$ & 314 & 34 & 36 \\
\hline QC, Québec City & $\begin{array}{l}\text { Hôpital de l'Enfant-Jésus, Centre } \\
\text { hospitalier affilié universitaire } \\
\text { de Québec }\end{array}$ & I & $\begin{array}{l}\text { Greater Québec City Area, } \\
\text { Eastern QC, Northern NB }\end{array}$ & 459 & 18 & 50 \\
\hline QC, Montréal & Hôpital de Sacré-Coeur de Montréal & I & $\begin{array}{l}\text { Western QC. Only referral } \\
\text { centre for ventilator } \\
\text { dependant patients with SCI. }\end{array}$ & 454 & $\dagger$ & 81 \\
\hline NS, Halifax & $\begin{array}{l}\text { Halifax Infirmary, Queen Elizabeth II } \\
\text { Health Sciences Centre }\end{array}$ & I & Atlantic Provinces & 406 & 16 & 19 \\
\hline
\end{tabular}

*For isolated injuries.

${ }^{\dagger}$ None specifically allocated for SCI.

SCI, spinal cord injury; tSCI, traumatic spinal cord injury; BC, British Columbia; AB, Alberta; SK, Saskatchewan; MB, Manitoba; ON, Ontario; QC, Québec; NS, Nova Scotia; LHIN, Local Health Integration Network. 
Table 2. Overview of the Rehabilitation Facilities in Canada Participating in the Survey

\begin{tabular}{|c|c|c|c|c|c|}
\hline Province/city & Facility & Regions served & $\begin{array}{l}\text { Total } \\
\text { number } \\
\text { of beds }\end{array}$ & $\begin{array}{l}\text { Beds } \\
\text { available } \\
\text { for SCI } \\
\text { admissions }\end{array}$ & $\begin{array}{l}\text { Admissions } \\
\text { of } t \text { SCI }\end{array}$ \\
\hline BC, Vancouver & GF Strong Rehabilitation Centre & BC, Yukon & 78 & $24-29$ & 96 \\
\hline $\mathrm{AB}$, Edmonton & Glenrose Rehabilitation Hospital & $\begin{array}{c}\text { Northern AB, Northwest } \\
\text { Territories, Northeast } \\
\text { BC, Northwest SK }\end{array}$ & 244 & 15 & 44 \\
\hline AB, Calgary & Foothills Hospital & Calgary, Southern AB & 45 & $12-18$ & 31 \\
\hline SK, Saskatoon & Saskatoon City Hospital & Northern SK & 32 & 16 & 15 \\
\hline MB, Winnipeg & Winnipeg Health Sciences Centre & $\begin{array}{l}\text { MB, Northwestern ON, } \\
\text { Nunavut }\end{array}$ & 31 & 13 & 27 \\
\hline ON, Toronto & $\begin{array}{l}\text { Toronto Rehabilitation } \\
\text { Institute, Lyndhurst Centre }\end{array}$ & $\begin{array}{l}\text { Northern ON, Greater } \\
\text { Toronto Area }\end{array}$ & $57-60$ & $57-60$ & 95 \\
\hline ON, London & $\begin{array}{l}\text { Parkwood Hospital, } \\
\text { St. Joseph's Health Care }\end{array}$ & Southwestern ON & 118 & 15 & 33 \\
\hline ON, Ottawa & $\begin{array}{l}\text { The Ottawa Hospital, } \\
\text { The Rehabilitation Centre }\end{array}$ & $\begin{array}{l}\text { Champlain LHIN, } \\
\text { Baffin Island }\end{array}$ & 58 & 24 & 27 \\
\hline ON, Hamilton & Hamilton Health Sciences Centre & $\begin{array}{l}\text { Hamilton Niagara } \\
\text { Haldimand Brant LHIN }\end{array}$ & 76 & 12 & 24 \\
\hline QC, Québec City & $\begin{array}{l}\text { Institut de réadaptation en } \\
\text { déficience physique de Québec }\end{array}$ & Eastern QC & 135 & 26 & 51 \\
\hline QC, Montréal & $\begin{array}{l}\text { Centre de réadaptation } \\
\text { Lucie-Bruneau }\end{array}$ & $\begin{array}{l}\text { Inpatients - Western QC; } \\
\text { Outpatients - Montréal } \\
\text { region only }\end{array}$ & 18 & 15 & 11 \\
\hline QC, Montréal & $\begin{array}{l}\text { Institut de réadaptions } \\
\text { Gingras-Lindsay-de-Montréal }\end{array}$ & $\begin{array}{l}\text { tSCI - Western QC; tetraplegic } \\
\text { with ventilator dependency- } \\
\text { all QC; ntSCI - Montréal only }\end{array}$ & 197 & 25 & 80 \\
\hline NS, Halifax & Nova Scotia Rehabilitation Centre & Atlantic Provinces & 60 & 20 & 36 \\
\hline NB, Fredericton & $\begin{array}{l}\text { Stan Cassidy Centre for } \\
\text { Rehabilitation }\end{array}$ & NB, NS, Prince Edward Island & 22 & 10 & 11 \\
\hline
\end{tabular}

SCI, spinal cord injury; tSCI, traumatic spinal cord injury; BC, British Columbia; AB, Alberta; SK, Saskatchewan; MB, Manitoba; ON, Ontario; QC, Québec; NS, Nova Scotia; LHIN, Local Health Integration Network; ntSCI, non-traumatic spinal cord injury.

admission into a SCI rehabilitation facility were reported. Broadly, there was little consensus among facilities with regard to admission criteria. Medical stability of the patient was identified as the most common criterion for admission. Criteria directly related to the provision of rehabilitation services (e.g., the patient's potential to achieve identifiable rehabilitation goals, their tolerance for activity)

Table 3. Structure Attributes of Acute Care and Rehabilitation Facilities

\begin{tabular}{lcc}
\hline Structure attributes & $\begin{array}{c}\text { Acute facilities } \\
(\mathrm{n}=15)\end{array}$ & $\begin{array}{c}\text { Rehabilitation } \\
\text { facilities }(\mathrm{n}=14)\end{array}$ \\
\hline $\begin{array}{c}\text { Number of admissions } \\
\quad(12-\text { month period) }\end{array}$ & $\begin{array}{c}\text { Range 17-104 } \\
\text { (median 39) }\end{array}$ & $\begin{array}{c}\text { Range 11-96 } \\
\text { (median 32) }\end{array}$ \\
$\begin{array}{l}\text { Number of units/wards } \\
\text { admitting patients }\end{array}$ & & \\
$\quad$ with SCI* & 6 & 9 \\
1 unit or ward & 7 & 3 \\
2 units or wards & 2 & 2 \\
3 or more units or wards & 8 & 10 \\
Group patients & 3 & 3 \\
$\begin{array}{l}\text { Acute and rehabilitation } \\
\text { care within same center }\end{array}$ & N/A & 13 \\
$\begin{array}{l}\text { Outpatient rehabilitation } \\
\text { program }\end{array}$ & & \\
\hline
\end{tabular}

*Excluding intensive care unit and step-down unit. SCI, spinal cord injury. were only required by half of the participating facilities. Almost all facilities reported availability of an outpatient rehabilitation program (Table 3); however, information related to outpatient services was not collected for the study.

\section{Challenges with regard to SCI patient care}

Acute and rehabilitation facilities across Canada identified a number of challenges with providing SCI patient care (Table 5). Lack of resources (e.g., bed availability, staffing, equipment) both within the facility and in later stages of care were reported to be key challenges. Discharge processes, including discharge planning and admission criteria, were also noted as challenges by both acute and rehabilitation facilities. In addition, acute facilities reported lack of availability of structures/services to provide specialized care and

Table 4A. Service Attributes of Acute Care Facilities

\begin{tabular}{lc}
\hline Service attributes & $\begin{array}{c}\text { Acute facilities } \\
(\mathrm{n}=15)\end{array}$ \\
\hline $\begin{array}{c}\text { Treats traumatic and non-traumatic } \\
\text { spinal cord injury }\end{array}$ & $13 *$ \\
$\begin{array}{l}\text { Magnetic resonance imaging access } \\
24 \mathrm{~h} / 7 \text { days }\end{array}$ & 12 \\
Spine surgeon on call $24 \mathrm{~h} / 7$ days & $12 *$ \\
\hline
\end{tabular}

*Missing data from two facilities 
Table 4B. Service Attributes of Rehabilitation Facilities

\begin{tabular}{lc}
\hline Service attributes & $\begin{array}{c}\text { Rehabilitation } \\
\text { facilities }(\mathrm{n}=14)\end{array}$ \\
\hline Physiatry consultation in acute care & $\begin{array}{c}11 / 15 \text { of acute } \\
\text { centers }\end{array}$ \\
Treats traumatic and non-traumatic & 14 \\
spinal cord injury & \\
Admission criteria & 10 \\
Medically stable & 7 \\
Potential to achieve & \\
$\quad$ identifiable goals & \\
Activity tolerance & 3 \\
1+ hour & 3 \\
3+ hours & 1 \\
$\quad$ Yes, but no specific hour & \\
$\quad$ requirement & 6 \\
Cognitive ability & 6 \\
Willingness to participate & 5 \\
Discharge planning & \\
Age & 15 other criteria \\
14+ & were identified \\
16+ & \\
Requires therapy in two or & \\
more disciplines & \\
Patient must not display & \\
aggressive behaviors & \\
Ventilator status & \\
Other & 4 \\
&
\end{tabular}

insufficient SCI specific knowledge as barriers. For example, one facility noted that "when questioned about the greatest challenges to SCI patient care, most individuals did not volunteer any challenges due to the fact that patients with SCI are not grouped and therefore are not identified as a specific patient group." Other challenges identified by both acute and rehabilitation facilities included support for research and data management, communication between clinicians, and the management of complex diagnoses and secondary complications.

\section{Discussion}

The continuum of care for persons sustaining a tSCI involves prehospital, acute, rehabilitation and community phases of care. The purpose of this study was to describe tSCI care provided in 15 acute and 14 rehabilitation facilities across eight Canadian provinces. Results from the survey revealed not only similarities in the basic structure, breadth and population of regions served (based on the facility capacity) and the provision of general services, but also some differences in the degree of specialization of care for individuals with tSCI. An overview of key challenges with structures and services and potential strategies is provided in Table 6 .

\section{Relation to previous literature}

Given that tSCI is a critical and severe injury, it is not surprising that 14 of the 15 acute facilities are recognized or are operating as Level I trauma centers (Table 1). Parent and colleagues ${ }^{3}$ recommended that specialized SCI facilities are inside or within close proximity to Level I trauma centers to ensure patients with tSCI
Table 5. Greatest Challenges in Spinal Cord Injury Care for Acute and Rehabilitation Facilities

\begin{tabular}{lcc}
\hline Challenge & $\begin{array}{c}\text { Acute facilities } \\
(\mathrm{n}=15)\end{array}$ & $\begin{array}{c}\text { Rehabilitation } \\
\text { facilities }(\mathrm{n}=14)\end{array}$ \\
\hline Resources - acute & 9 & - \\
Resources - rehabilitation & 11 & 4 \\
Resources - community & 3 & 10 \\
Discharge process & 3 & 4 \\
SCI specific knowledge & 3 & 1 \\
Hospital structure/services & 3 & - \\
$\quad$ to provide specialized care & & 4 \\
Other & 3 & \\
\hline
\end{tabular}

SCI, spinal cord injury.

have access to these services. Results from this survey suggest the present acute care facilities provide this type of specialized care.

Volume of admissions has been identified as an important attribute in trauma centers ${ }^{35,36}$ and in a wide variety of conditions, including stroke, ${ }^{37}$ acute myocardial infarction, ${ }^{38}$ AIDS,,${ }^{39}$ as well as in $\mathrm{tSCI}^{3}$; however the actual minimum number or threshold of admissions required for tSCI has not been quantified. ${ }^{3,40} \mathrm{~A}$ few studies examining specialized surgical treatments in oncology ${ }^{41,42}$ and acquired brain injury ${ }^{43}$ suggest that reduced operative mortality rates of their specialized patient populations would be observed if centers admit critical volumes of 20 to $30^{41-43}$ cases per annum. The present results revealed that the size of the acute and rehabilitation facilities, the number of beds available for SCI admissions, and the number of admissions varied across Canada. Some instances of higher admission rates were observed alongside reports of greater geographical extent and population of regions served (Table 1). In larger provinces, such as Ontario, the presence of multiple intra-provincial acute care and rehabilitation facilities that admit patients with tSCI could confound this connection. The importance of requiring a certain volume of admissions to provide specialized care was noted specifically by one facility where with "small numbers of patients with SCI overall, it is hard to maintain expertise." Further examination into the critical volume of admissions for SCI and the impact on outcomes is needed.

Parent and colleagues ${ }^{3}$ also commented on the importance of having a "spinal unit," which encompasses both the physical location and the provision of care by an interdisciplinary team (e.g., physiotherapists, nurses, social workers). Based on the survey responses, this type of program appears to be common in Canadian centers, and is present in 10 of the 14 rehabilitation facilities and eight of the 15 acute facilities (Table 3). While the definition of (or what constitutes) an ideal program or service for patients sustaining a tSCI is still unknown, the introduction of SCI Standards for both acute and rehabilitation phases of care in 2012 (updated in 2017) by Accreditation Canada is a major development. ${ }^{29,30}$

\section{Implications}

Institutions seeking accreditation under the SCI Standards of Care will be required to demonstrate that best practices are in place to address the unique needs of the SCI patient population. ${ }^{29,30}$ Required organizational practices or high priority criteria in the SCI Standards, that have been recognized as relevant for SCI care include using validated measures to perform accurate and appropriate assessment of patients to determine neurological, cognitive, and autonomic function, and to predict risk of secondary complications. 
Table 6. Summary of Main Challenges and Strategies Related to Providing Spinal Cord Injury (SCI) Care

\begin{tabular}{|c|c|c|}
\hline Attribute & Challenge & Strategy \\
\hline $\begin{array}{l}\text { Volume of } \\
\text { admissions }\end{array}$ & $\begin{array}{l}\text { Critical volume to maximize outcomes } \\
\text { and maintain expertise is unknown }\end{array}$ & Further examination of critical volumes for SCI \\
\hline Spinal unit & $\begin{array}{l}\text { Definition of ideal program or service } \\
\text { is unknown }\end{array}$ & $\begin{array}{l}\text { Accreditation of facilities under the Accreditation Canada SCI } \\
\text { Standards of Care }\end{array}$ \\
\hline \multirow{2}{*}{ Integrated care } & Varied admission criteria to rehabilitation & Further examination of criteria for admission \\
\hline & $\begin{array}{l}\text { Transitions between phases of care are not } \\
\text { streamlined }\end{array}$ & $\begin{array}{l}\text { Identification, classification and measurement of discharge barriers } \\
\text { Implementation of structured, systematic transfer agreements } \\
\text { Evaluation of alignment of SCI care with Accreditation } \\
\text { Canada's Trauma Distinction Program }\end{array}$ \\
\hline
\end{tabular}

Facilities can demonstrate compliance by providing staff with validated assessment measures, providing training programs on the use of assessment tools, and by having protocols in place for documentation and sharing of results with patients and other service providers. As of February 2017, the SCI Standards have been adopted by five acute, five rehabilitation, and two integrated facilities within the RHSCIR Network. ${ }^{44}$ Studies currently are being planned to assess how current care provision in acute and rehabilitation facilities aligns with the SCI Standards produced by Accreditation Canada. More importantly, however, will be future well-designed prospective controlled studies to determine if these standards of care produces positive outcomes for both the patient and the healthcare system. ${ }^{45}$

Early referral to rehabilitation was an additional feature proposed to represent specialized care in SCI. ${ }^{3}$ Three facilities participating in this survey have acute and rehabilitation care located within one site, however, physical location may not be the only indicator of an integrated system of care. The transfer of patients from acute to rehabilitation is commonly initiated by a physiatry consultation during acute care. However, it is interesting to note that the actual criteria for admission to the inpatient rehabilitation facilities varied, both within and among provinces. For example, 10/14 rehabilitation facilities required patients to be medically stable but only $4 / 14$ required patients to need therapy in two or more disciplines (Table 4B). Further examination of referral mechanisms, admission criteria, and the existence of transfer agreements between facilities are therefore needed.

Smooth transitions between acute and rehabilitation phases of care also may be hindered by discharge barriers. A recent article by New and colleagues ${ }^{46}$ defined discharge barriers from rehabilitation care as having occurred "when the treating team believes that there are no longer any goals of therapy or treatment that require inpatient rehabilitation, and yet the patient is unable to be discharged," and categorized barriers as intrinsic or extrinsic. Many of the acute and rehabilitation facilities identified extrinsic discharge barriers, including downstream resources and discharge processes, as key challenges for SCI patient care (e.g., bed availability, equipment approval, accessible housing; Table 5). Addressing discharge barriers may therefore be an important intervention target toward improving care, but classification and measurement of barriers are not currently collected for acute or rehabilitation facilities within the Canadian SCI Network. Providing care within one comprehensive system and the implementation of structured, systematic transfer agreements may streamline transition from acute to rehabilitation, but further study is needed.

Streamline transition throughout the care continuum by adopting a system-level view of care after trauma is being promoted by Accreditation Canada in the Trauma Distinction program, which includes two sets of standards; the Trauma Center Standards and the Trauma System Standards. ${ }^{47}$ The program was released in 2014 and developed in partnership with the Trauma Association of Canada. The focus of the Trauma System Standards will be to evaluate how pre-hospital, acute, and rehabilitation services are integrated. As tSCI is a subset of the trauma population, evaluation of alignment of tSCI care with the Trauma System Standards is warranted, and our survey addresses some of the topics within the standards. Further consideration also will be required to determine how transferable these standards are to other countries as well as to specific types of tSCI, since there is emerging evidence to suggest that even within a health condition such as tSCI, there is considerable heterogeneity among specific types of injuries. ${ }^{48}$

Once discharged to the community, regular comprehensive outpatient follow-up care and addressing unmet needs has been linked to perceived improvements in health, independence, overall improvements in patient satisfaction, and enhanced quality of life for persons with SCI. ${ }^{49,50}$ Of the 14 rehabilitation facilities surveyed, 13 reported having an outpatient program (Table 3). Outpatient services represent a significant proportion of the rehabilitation journey and utilization of outpatient rehabilitation services for this patient population warrants further investigation.

\section{Next steps/gaps}

The results of this survey have directly contributed to the design and development of the ACT simulation model for tSCI care. ${ }^{31}$ Further, the responses also have helped to enhance and refine the next version of survey questions, which was launched recently in the ACT International Study examining SCI care across international jurisdiction. Finally, studies are ongoing to further examine if there are any differences in the types of patients who are not being referred to major SCI centers. Results from these additional studies will help further define specialized care for tSCI and will be required for SCI centers to be recognized as an accredited SCI center.

\section{Limitations}

Data from the survey were compiled from various data sources (registries, expert opinion, and administrative reports) leading to a unique look at SCI care but also may produce inconsistencies in how the questions were interpreted and answered. Extensive data quality checks were included as part of this study, but there was still the possibility of inaccurate reporting. Data from this survey only represented 1 calendar year (12 months) but often the data sources did not align exactly with data covering either an earlier or later time period. It also is critical to note that not all RHSCIR facilities were able to complete the survey (i.e., excludes New Brunswick acute and Newfoundland acute and rehabilitation); and of the 
facilities surveyed as part of this study, they only represented a subset of the major trauma centers that admit patients with tSCI in Canada. It is estimated that the RHSCIR captures 60 to $70 \%$ of all acute tSCI based on comparisons with other national data sources (Canadian Institute for Health Information) but these data sources have been shown to be variable in classifying spinal injuries. ${ }^{51}$ These estimates of RHSCIR capture rate need to be carefully compared with the published study, ${ }^{52}$ which reported the incidence of tSCI in Canada to be approximately 1300 by modeling data from one province (Alberta) ${ }^{53}$ to obtain a national perspective.

\section{Conclusion}

In summary, results from a survey of 15 acute care and 14 rehabilitation facilities in Canada suggest that patients with tSCI receive the benefits of standardized care provided by trauma centers and programs; however, more research is needed to determine if further specialization for managing SCI is needed. The recent release of the Accreditation Canada SCI Standards for hospital acute and rehabilitation services will help facilities ensure that the unique needs of patients with SCI will be met. Standardized care customized to specific types of injuries will likely produce positive outcomes for both the patient and the healthcare system.

\section{Acknowledgments}

The authors thank the Rick Hansen Institute RHSCIR Team (Suzanne Humphreys, Daniel Rogers, Kristen Walden, Jayson Shurgold, Jessica Eapen, Jerome Buenaventura, Tova Plashkes, Arlene Aspinall, Cynthia Morin, and Shannon Sproule), the RHSCIR Network, and all facilities who participated in the survey (Vancouver General Hospital, G.F. Strong Rehabilitation Centre, Foothills Medical Centre, Royal Alexandra Hospital, University of Alberta Hospital, Glenrose Rehabilitation Hospital, Royal University Hospital, Saskatoon City Hospital, Winnipeg Health Sciences Centre, St. Michael's Hospital, Sunnybrook Health Sciences Centre, Toronto Western Hospital, Toronto Rehabilitation Institute-Lyndhurst Centre, Hamilton Health Sciences Centre, Victoria Hospital (London), Parkwood Hospital (London), The Ottawa Hospital-Civic Campus, The Ottawa Hospital Rehabilitation Centre, Hôpital de l'Enfant Jésus, Institut de réadaptation en déficience physique de Québec, Hôpital du Sacré-Coeur de Montréal, Centré de réadaptation Lucie-Bruneau, Institut de réadaptation Gingras-Lindsay-de-Montréal, QEII Health Sciences Centre, Nova Scotia Rehabilitation Centre, and Stan Cassidy Centre for Rehabilitation).

\section{Author Disclosure Statement}

This study was supported by financial contributions from the Rick Hansen Institute, the Ontario Neurotrauma Foundation, and the Government of Canada through Health Canada and Western Economic Diversification Canada.

\section{References}

1. Smetana, G.W., Landon, B.E., Bindman, A.B., Burstin, H., Davis, R.B., Tjia, J., Rich, E.C., and Deaconess, B.I. (2007). A comparison of outcomes resulting from generalist vs specialist care for a single discrete medical condition. Arch. Intern. Med. 167, 10-20.

2. National Academy of Sciences (U.S.) and National Research Council (U.S.) Committee on Trauma; National Academy of Sciences (U.S.) and National Research Council (U.S.) Committee on Shock. (1966) Accidental Death and Disability: The Neglected Disease of Modern Society. Washington (DC): National Academies Press (US).
3. Parent, S., Barchi, S., LeBreton, M., Casha, S., and Fehlings, M.G. (2011). The impact of specialized centers of care for spinal cord injury on length of stay, complications, and mortality: a systematic review of the literature. J. Neurotrauma 28, 1363-1370.

4. Donovan, W.H. (2007). Donald Munro Lecture. Spinal cord injurypast, present, and future. J. Spinal Cord Med. 30, 85-100.

5. Frankel, H. (1999). 100 years after his birth Guttmann's message lives on. Spinal Cord 37, 461-462.

6. Amin, A., Bernard, J., Nadarajah, R., Davies, N., Gow, F., and Tucker, S. (2005). Spinal injuries admitted to a specialist centre over a 5-year period: a study to evaluate delayed admission. Spinal Cord 43, 434-437.

7. Aung, T.S. and Masry, W.S. (1997). Audit of a British centre for spinal injury. Spinal Cord 35, 147-151.

8. Oakes, D., Wilmot, C.B., Hall, K.M., and Sherck, J.P. (1990). Benefits of early admission to a comprehensive trauma center for patients with spinal cord injury. Arch. Phys. Med. Rehabil. 71, 637-643.

9. Mackenzie, E.J., Rivara, F.P., Jurkovich, G.J., Nathens, A.B., Egleston, B.L., Salkever, D.S., Frey, K.P., and Scharfstein, D.O. (2008). The impact of trauma-center care on functional outcomes following major lower-limb trauma. J. Bone Joint Surg. Am. 90, 101-109.

10. Demetriades, D., Martin, M., Salim, A., Rhee, P., Brown, C., and Chan, L. (2005). The effect of trauma center designation and trauma volume on outcome in specific severe injuries. Ann Surg. 242, 512-517.

11. Gabbe, B.J., Simpson, P.M., Sutherland, A.M., Wolfe, R., Fitzgerald, M.C., Judson, R., and Cameron, P.A. (2012). Improved functional outcomes for major trauma patients in a regionalized, inclusive trauma system. Ann. Surg. 255, 1009-1015.

12. Moore, L., Turgeon, A.F., Lauzier, F., Émond, M., Berthelot, S., Clément, J., Bourgeois, G., and Lapointe, J. (2015). Evolution of patient outcomes over 14 years in a mature, inclusive Canadian trauma system. World J. Surg. 39, 1397-1405.

13. Moore, L., Hanley, J., Turgeon, A.F., and Lavoie, A. (2010). Evaluation of the long-term trend in mortality from injury in a mature inclusive trauma system. World J. Surg. 34, 2069-2075.

14. DeVivo, M.J., Kartus, P.L., Stover, S.L., and Fine, P.R. (1990). Benefits of early admission to an organised spinal cord injury care system. Paraplegia 28, 545-555.

15. Ploumis, A., Kolli, S., Patrick, M., Owens, M., Beris, A., and Marino, R.J. (2011). Length of stay and medical stability for spinal cordinjured patients on admission to an inpatient rehabilitation hospital: a comparison between a model SCI trauma center and non-SCI trauma center. Spinal Cord 49, 411-45.

16. Yarkony, G.M., Bass, L.M., Keenan, V., and Meyer, P.R. (1985). Contractures complicating spinal cord injury: incidence and comparison between spinal cord centre and general hospital acute care. Paraplegia 23, 265-271.

17. Tator, C.H., Duncan, E.G., Edmonds, V.E., Lapczakl, L.I., and Andrews, D.F. (1995). Neurological recovery, mortality and length of stay after acute spinal cord injury associated with changes in management. Paraplegia 33, 254-262.

18. Sumida, M., Fujimoto, M., Tokuhiro, A., Tominaga, T., Magara, A., and Uchida, R. (2001). Early rehabilitation effect for traumatic spinal cord injury. Arch. Phys. Med. Rehabil. 82, 391-395.

19. Scivoletto, G., Morganti, B., and Molinari, M. (2005). Early versus delayed inpatient spinal cord injury rehabilitation: an Italian study. Arch. Phys. Med. Rehabil. 86, 512-516.

20. Heinemann, A.W., Yarkony, G.M., Roth, E.J., Lovell, L., Hamilton, B., Ginsburg, K., Brown, J.T., Meyer, P.R., and Allen, W. (1989). Functional outcome following spinal cord injury. A comparison of specialized spinal cord injury center vs general hospital short-term care. Arch. Neurol. 46, 1098-1102.

21. Aito, S. (2003). Complications during the acute phase of traumatic spinal cord lesions. Spinal Cord 41, 629-635.

22. Celani, M.G., Spizzichino, L., Ricci, S., Zampolini, M., and Franceschini, M. (2001). Spinal cord injury in Italy: a multicenter retrospective study. Arch. Phys. Med. Rehabil. 82, 589-596.

23. New, P., Townson, A., Scivoletto, G., Post, M.W., Eriks-Hoogland, I., Gupta, A., Smith, E., Reeves, R.K., and Gill, Z.A. (2013). International comparison of the organisation of rehabilitation services and systems of care for patients with spinal cord injury. Spinal Cord 51, 33-39.

24. van Langeveld, S.A., Post, M.W., van Asbeck, F.W., Gregory, M., Halvorsen, A., Rijken, H., Leenders, J., Postma, K., and Lindeman, E. 
(2011). Comparing content of therapy for people with a spinal cord injury in postacute inpatient rehabilitation in Australia, Norway, and the Netherlands. Phys. Ther. 91, 210-224.

25. Divanoglou, A., Seiger, A., and Levi, R. (2010). Acute management of traumatic spinal cord injury in a Greek and a Swedish region: a prospective, population-based study. Spinal Cord 48, 477-482.

26. Lenehan, B., Dvorak, M.F., Madrazo, I., Yukawa, Y., and Fisher, C.G. (2010). Diversity and commonalities in the care of spine trauma internationally. Spine 35, S174-S179.

27. Fromovich-Amit, Y., Biering-Sørensen, F., Baskov, V., Juocevicius, A., Hansen, H. V, Gelernter, I., Hart, J., Baskov, A., Dreval, O. Terese, P., and Catz, A. (2009). Properties and outcomes of spinal rehabilitation units in four countries. Spinal Cord 47, 597-603.

28. Craven, C., Verrier, M., Balioussis, C., Wolfe, D., Hsieh, J., Noonan, V., Rasheed, A., and Cherban, E. (2012). Rehabilitation Environmental Scan Atlas: Capturing Capacity in Canadian SCI Rehabilitation. Rick Hansen Institute: Vancouver, BC.

29. Accreditation Canada. (2017). Qmentum Program: Spinal Cord Injury Acute Services. Ottawa.

30. Accreditation Canada. (2017). Qmentum Program: Spinal Cord Injury Rehabilitation Services. Ottawa.

31. Noonan, V.K., Soril, L., Atkins, D., Lewis, R., Santos, A., Fehlings, M.G., Burns, A.S., Singh, A., and Dvorak, M.F. (2012). The application of operations research methodologies to the delivery of care model for traumatic spinal cord injury: the access to care and timing project. J. Neurotrauma 29, 2272-2282.

32. Noonan, V., Kwon, B., Soril, L., Fehlings, M., Hurlbert, R., Townson, A., Johnson, M., and Dvorak, M. (2012). The Rick Hansen Spinal Cord Injury Registry (RHSCIR): a national patient-registry. Spinal Cord 50, 22-27.

33. Statistics Canada. (2011). Population and dwelling count highlight tables. www.12.statcan.gc.ca/census-resensement/2011/dp-pd/hlt-fst/ pd-pl/Highlights-eng.cfm?LANG=Eng (last accessed January 9, 2017).

34. Capital Health. QEII Health Sciences Centre. Nov. Scotia Heal. Auth. Available at: www.cdha.nshealth.ca/about-us/our-facilities/qeii-healthsciences-centre. Accessed July 2, 2015.

35. Bell, T.M., Boustany, K.C., Jenkins, P.C., and Zarzaur, B.L. (2015). The relationship between trauma center volume and in-hospital outcomes. J. Surg. Res. 196, 350-357.

36. Bennett, K.M., Vaslef, S., Pappas, T.N., and Scarborough, J.E. (2011). The volume-outcomes relationship for United States Level I trauma centers. J. Surg. Res. 167, 19-23.

37. Saposnik, G., Baibergenova, A., O’Donnell, M., Hill, M.D., Kapral, M.K., and Hachinski, V. (2007). Hospital volume and stroke outcome: does it matter? Neurology 69, 1142-1151.

38. Ross, J.S., Normand, S., Wang, Y., Ko, D.T., Chen, J., Drye, E.E., Keenan, P.S., Lichtman, J.H., Bueno, H., Schreiner, G.C., and Krumholz, H.M. (2010). Hospital volume and 30-day mortality for three common medical conditions. N. Engl. J. Med. 362, 1110 1118.

39. Hogg, R.S., Raboud, J., Bingham, M., Montaner, J.S., O’Shaugnessy, M., and Schechter, M.T. (1998). Relation between hospital HIV/AIDS caseload and mortality among persons with HIV/AIDS in Canada. Clin. Investig. Med. 21, 27-32.

40. Macias, C.A., Rosengart, M.R., Puyana, J.C., Linde-Zwirble, W.T., Smith, W., Peitzman, A.B., and Angus, D.C. (2009). The effects of trauma center care, admission volume, and surgical volume on paralysis after traumatic spinal cord injury. Ann. Surg. 249, 10-17.

41. Bristow, R.E., Palis, B.E., Chi, D.S., and Cliby, W.A. (2010). The National Cancer Database report on advanced-stage epithelial ovarian cancer: impact of hospital surgical case volume on overall survival and surgical treatment paradigm. Gynecol. Oncol. 118, 262-267.

42. Metzger, R., Bollschweiler, E., Vallböhmer, D., Maish, M., Demeester, T.R., and Hölscher, A.H. (2004). High volume centers for esophagectomy: what is the number needed to achieve low postoperative mortality? Dis. Esophagus 17, 310-314.

43. Solomon, R.A., Mayer, S.A., and Tarmey, J.J. (1996). Relationship between the volume of craniotomies for cerebral aneurysm performed at New York state hospitals and in-hospital mortality. Stroke 27, 13-17.

44. Rick Hansen Institute. (2017). Accreditation Standards. Rick Hansen Inst. Available at: www.rickhanseninstitute.org/work/our-projectsinitiatives/accreditation-standards. Accessed April 21, 2017.

45. Bagnall, A., Jones, L., Duffy, S., and Riemsma, R. (2008). Spinal fixation surgery for acute traumatic spinal cord injury (Review). Cochrane Database Syst. Rev. 23.

46. New, P.W., Cameron, P.A., Olver, J.H., and Stoelwinder, J.U. (2013). Defining barriers to discharge from inpatient rehabilitation, classifying their causes, and proposed performance indicators for rehabilitation patient flow. Arch. Phys. Med. Rehabil. 94, 201-208.

47. Accreditation Canada. (2014). Trauma Distinction Information Package. Ottawa.

48. Dvorak, M.F., Noonan, V.K., Fallah, N., Fisher, C.G., Rivers, C.S. Ahn, H., Tsai, E.C., Linassi, G., Christie, S.D., Attabib, N., Hurlbert, R.J., Fourney, D.R., Johnson, M.G., Fehlings, M.G., Drew, B., Bailey, C.S., Paquet, J., Parent, S., Townson, A., Ho, C., Craven, B.C., Gagnon, D., Tsui, D., Fox, R., Mac-Thiong, J.M., and Kwon, B.K. (2014). Minimizing errors in acute traumatic spinal cord injury trials by acknowledging the heterogeneity of spinal cord anatomy and injury severity: an observational Canadian cohort analysis. J. Neurotrauma 31, 1540-1547.

49. Dunn, M., Love, L., and Ravesloot, C. (2000). Subjective health in spinal cord injury after outpatient healthcare follow-up. Spinal Cord 38, 84-91.

50. Sweet, S.N., Noreau, L., Leblond, J., and Dumont, F.S. (2014). Understanding quality of life in adults with spinal cord injury via SCIrelated needs and secondary complications. Top. Spinal Cord Inj. Rehabil. 20, 321-328.

51. Noonan, V.K., Thorogood, N.P., Fingas, M., Batke, J., Bélanger, L., Kwon, B.K., and Dvorak, M.F. (2013). The validity of administrative data to classify patients with spinal column and cord injuries. J. Neurotrauma 30, 173-180.

52. Noonan, V.K., Fingas, M., Farry, A., Baxter, D., Singh, A., Fehlings, M.G., and Dvorak, M.F. (2012). Incidence and prevalence of spinal cord injury in Canada: a national perspective. Neuroepidemiology 38 , 219-226.

53. Dryden, D.M., Saunders, L.D., Rowe, B.H., May, L.A., Yiannakoulias, N., Svenson, L.W., Schopflocher, D.P., and Voaklander, D.C. (2003). The epidemiology of traumatic spinal cord injury in Alberta, Canada. Can. J. Neurol. Sci. 30, 113-121.

\author{
Address correspondence to: \\ Vanessa K. Noonan, PhD, PT \\ Rick Hansen Institute \\ 6400-818 West 10th Avenue \\ Vancouver, British Columbia \\ V5Z 1M9 Canada
}

E-mail:vnoonan@rickhanseninstitute.org 